\title{
Problems and Useful Techniques: My Experiences in Teaching Courses in Argumentation, Informal Logic and Critical Thinking
}

\section{Douglas Walton}

\author{
Department of Philosophy \\ University of Winnipeg \\ 515 Portage Avenue \\ Winnipeg, Manitoba \\ Canada R3B 2E9 \\ E-mail: walton@io.uwinnipeg.ca
}

\section{Types of Courses}

There are three levels of courses that I routinely teach that involve informal logic. One is a first-year course called "Introduction to Logical Reasoning." The next is a second-year course, "Logic." It is open to anyone, but is a (highly recommended) requirement for philosophy majors and honors students. It contains about a fifty-fifty balance between formal and informal logic.The remaining one is a third-year course called "Argumentation," which attracts senior students from various disciplines, but often contains quite a few honors philosophy students. It contains little formal logic. My experience is that teaching the latter two courses tends to go well, possibly because the students tend to come from among our better students, and they are well-motivated to learn the subject matter. Teaching the first-year course tends to be more uneven. It can be problematic some years, and can easily go wrong.The reason may be that this course gets many students who are poorly prepared and motivated, and who may drop out during the first term. This course often gets quite a few very good students as well, and the mixture seems to create problems, especially in the first term, until things settle down a bit. What I have been noticing is more of a drift towards a "high school" atmosphere in this class. Getting some of the students to pay attention, or to grasp points that I would have considered very elementary in the past, seems to be a problem.

The second year Logic course is very typical, and not much different, I assume from what is taught at many universities. I have no especially innovative techniques used there, except to do plenty of exercises, and build the exams around them. The third year Argumentation course is more unusual. I know several colleagues at other universities who are teaching roughly comparable courses, but I think they are in a small minority. It is comparatively rare to find such a course taught at upper levels in the university curriculum. It is rare to find them taught at the graduate level. It is also extremely rare to see graduate students doing a thesis on a problem in this area (outside of a few centers, like the Department of Speech 
Communication and Rhetoric at the University of Amsterdam or the Philosophy Program at the University of Windsor). However, it is my own experience that this type of course can be highly successful, that there is a very useful technique for teaching it, and that this technique is not all that difficult to master or to implement.

\section{The Case Study Method}

In the Argumentation course, I do have an innovative method that has worked very well for me in the past seven years so. Over the years I gradually began to use this technique more and more. My technique is to build everything around the case study method. The classes begin with an exposition of general methods, but quickly turns to individual case studies of examples of argumentative discourse. I use examples from magazines, newspapers, news media, parliamentary debates, and all kinds of other sources. Instead of assigning an essay, I give students a specific text of discourse - for example, an argument from a newspaper column - and give them instructions on how to analyze it. Often a fallacy is involved, or some sort of argumentation that appears to contain a fallacy. The assignment is like an essay, but is directed to a specific case. I use different cases all the time, as I find good ones. The students like this way of doing assignments. They don't have to memorize things, as they typically have to in a conventional test. And they don't have to agonize about choosing an essay topic, and knowing how to proceed with it, as they typically do with a conventional essay assignment. From an instructor's point of view, the advantage is that plagiarism is reduced. The students can't just download something from the net, because each assignment is unique to the specifics of the case chosen for analysis. They have to work with the case they are given. But students seem to like this kind of assignment-maybe because it is different from their other course, or because they are not left on their own so much to get lost in tackling an essay topic where the problem is to try to cut down the huge unruly mass of relevant information they can find.

With this more advanced type of course on argumentation, 1 would highly recommend the case study method. 1 also used it in a graduate course on argumentation in the Deptartment of Communication Studies at Northwestern University in 1999, where it appeared to be quite successful. Certainly I got a lot of positive feedback from individual students. Many instructors in informal logic course may be already using something like the case study method. I would suggest possibly even going further in this direction, in the way that I have found successful with more senior students.

\section{Problems in Teaching Introductory Critical Thinking}

As for the pedagogical problem posed by the Intro. course, I wish I could say that I had a method or technique that has proved successful. But I do not, and from what $\mathrm{l}$ can see, especially by looking at the abundance of textbooks on critical thinking, I don't think anyone else has solved this problem either. Most of these 
students do not do well with the case study method. What they seem to need are simple mechanical procedures that they can apply without being stressed by borderline cases, or any doubts at all about what the "right" answer is. Many of these students have great difficulty grasping what an argument is, or that arguments are sometimes useful and necessary. Some of these students have a huge problem grasping the distinction between an explanation and argument. Many of them think that all arguments are really explanations. They can't articulate why, but they insist they are right, and sometimes it is the other students who best try to persuade them that they aren't right. But even they are not successful.

Many might say that these students are just not ready for critical thinking, and since they usually wind up dropping out anyway, or failing, that this outcome is the best thing, or is inevitable anyway. But I still feel that there is a way of reaching these students, but we just haven't found it yet. Whoever does find it will likely become rich and famous. But I do not yet know how it will be done, nor does anyone else in the field, as far as I can tell. There are two kinds of proposals that are plausible. One is to make the students do a lot of writing assignments based on analyses of argumentative passages, and then have the instructor go over these written assignments with each student. This kind of proposal is often suggested. But the problem is that it is costly to implement. It requires a lot of tutorial time. The second proposal is to set up a computerized learning program that the students can use alongside the regular lectures.

This second type of proposal may sound merely trendy. But I think that while it would not work well with higher level courses, it could be just the right thing that is needed at the introductory critical thinking level. As indicated above, there is a special kind of problem with this type of course. I think that the solution, when it comes, will be by means of interactive software that takes the beginner, step by step, though easy examples, and responds helpfully to guesses, questions and wrong answers. The use of such interactive software, along with an instructor and a textbook will, I think be the format that will provide the solution. This project is worth trying anyway. It has already been attempted, but all of the software I have examined so far is, in my opinion, unsuccessful, and a very long way from being successful. I wish I could carry out this project myself. But I lack the computer skills and the time needed to do it properly. It should be a group project, well funded, with participants who have the latest computer skills and the latest state of the art argumentation techniques. I would like to be involved, if there is anyone out there who has the right computer software writing skills and who is willing and able to spend enough time on this project.

\section{Recommendations on How to Proceed}

I am sure that the problems in teaching introductory courses in critical thinking I have described are not unique to my university. I am pretty confident in guessing that these problems are very widespread, or even universal. On the other hand, 
they are not unique to critical thinking courses. Introductory classes tend to be larger than upper-level courses. They have many more students who are just out of high school, and are struggling with the new experience of university classes. Even so, critical thinking is harder to teach than many courses, because it is a skills course. The instructor can't so easily retreat into the usual quantification and mechanization, making tests that use multiple-choice questions, or that simply require memorization of the textbook. As indicated above, I don't have any single solution to this problem that would easy to implement. All I have is to hold out the incentive that, in my opinion, solving it should be possible.

As for the senior level course in argumentation, here I have proposed what I think is a highly effective pedagogical method that can be applied right away, with some preparation. You might think that the same technique for the senior level course could "trickle down" to the introductory level course. But I do not think that will work, at least in any straightforward way. The key problem with the introductory critical thinking course is that the students, or many of them, are simply not ready for all the problems of interpreting a natural language text of discourse, and the judgment required to deal with all the vague borders of realistic cases of argumentation. They seem to need some sort of artificial structure composed of simple questions with clear answers. They need to begin with clear examples that illustrate, for example, the distinction between an argument and an explanation, and that don't introduce too many complications all at once. I don't see any reason why devising such a pedagogical method is impossible. But I just don't see any way to do it that is highly effective, or better than just proceeding by indirection. The best I can claim here is, though my own personal experiences over thirty years of teaching, to have formulated the problem in a way that may narrow down the range of plausible avenues to a solution.

But since we are engaged in teaching this type of course on very wide scale, the best to strive for is to try to work towards improving what we are already doing, on a day to day basis. What I have proposed above, however, is to consider a group research project to develop new methods that are partly based on the use of interactive computer software. Part of the project would be to test out and refine the methods arrived at, by using them on selected groups of students, as the project proceeds. Thus the project would combine teaching and research. I don't see any other way of moving ahead that is very likely to have any prospect of improving the current state of affairs in introductory critical thinking courses. 